$12-2013$

\title{
Minimal Medium for Optimal Growth and Lipid Production of the Microalgae Scenedesmus dimorphus
}

Colin Welter

Cleveland State University

Jacob Schwenk

Cleveland State University

Bônow Kanshand additional works at: https://engagedscholarship.csuohio.edu/encbe_facpub I'vveland State University

Part of the Chemical Engineering Commons

Hown daens Balargagn to this work benefit you? Let us know!

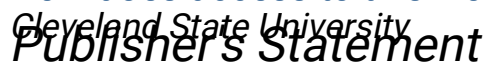

Jbisnisethe. Befepteq version of the following article: Welter, C. , Schwenk, J. , Kanani, B. , Van

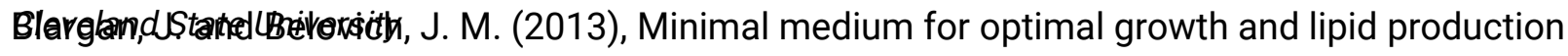
of the microalgae Scenedesmus dimorphus. Environ. Prog. Sustainable Energy, 32: 937-945. doi:10.1002/ep.11835, which has been published in final form at https://aiche.onlinelibrary.wiley.com/doi/10.1002/ep.11835

\section{Original Citation}

Welter C, Schwenk J, Kanani B, Van Blargan J, Belovich JM. Minimal Medium for Optimal Growth and Lipid Production of the Microalgae Scenedesmus dimorphus. Environ Prog Sustain Energy. 2013;32:937-945.

\section{Repository Citation}

Welter, Colin; Schwenk, Jacob; Kanani, Bahar; Van Blargan, John; and Belovich, Joanne M., "Minimal Medium for Optimal Growth and Lipid Production of the Microalgae Scenedesmus dimorphus" (2013). Chemical \& Biomedical Engineering Faculty Publications. 146.

https://engagedscholarship.csuohio.edu/encbe_facpub/146

This Article is brought to you for free and open access by the Chemical \& Biomedical Engineering Department at EngagedScholarship@CSU. It has been accepted for inclusion in Chemical \& Biomedical Engineering Faculty Publications by an authorized administrator of EngagedScholarship@CSU. For more information, please contact library.es@csuohio.edu. 


\title{
Minimal Medium for Optimal Growth and Lipid Production of the Microalgae Scenedesmus
} dimorphus

\author{
Colin Welter, ${ }^{a}$ Jacob Schwenk, ${ }^{a}$ Bahar Kanani, ${ }^{a}$ John Van Blargan, ${ }^{b}$ and Joanne M. Belovich ${ }^{\mathrm{a}}$ \\ ${ }^{a}$ Department of Chemical and Biomedical Engineering, Cleveland State University, Cleveland, $\mathrm{OH}$ 44115-2214; \\ j.belovich@csuohio.edu (for correspondence) \\ "Department of Mechanical Engineering, Cleveland State University, Cleveland, OH 44115-2214
}

Published online 18 September 2013 in Wiley Online Library (wileyonlinelibrary.com). DOI 10.1002/ep.11835

The culture of Scenedesmus dimorphus at the laboratory scale bas often been in standard microalgae media, such as $3 N$-Basal Bold medium $(3 N-B B)$, which contains 15 different chemicals. Given the extremely tight profit margins of largescale production of biofuel from microalgae, it is important to identify the minimally sufficient quantities of nutrients necessary to maximize lipid productivity. The individual and interactive effects of six groupings of the components of $3 \mathrm{~N}$ $B B$ medium on growth rate, lipid content, and total biomass yield of $\mathrm{S}$. dimorphus were determined. Trace metal and vitamin concentrations were reduced to $1 / 6$ the level of $3 \mathrm{~N}$ $B B$ medium without adversely affecting growth rates and biomass concentration, while concentrations of $\mathrm{CaCl}_{2}$ and $\mathrm{K}_{2} \mathrm{HPO}_{4} / \mathrm{KH}_{2} \mathrm{P}^{2} \mathrm{O}_{4}$ were reduced to $1 / 10$ that of $3 \mathrm{~N}-\mathrm{BB}$ without adversely affecting biomass and lipid concentrations. Both lipid productivity and lipid content were maximized at the lowest $\mathrm{NaNO}_{3}$ concentration (1/10 that in $\left.3 \mathrm{~N}-\mathrm{BB}\right)$ and independent of $\mathrm{MgSO}_{4}$ concentration, while the interaction of these two chemicals enhanced biomass concentration. (c) 2013 American Institute of Chemical Engineers Environ Prog, 32: 937-945, 2013

Keywords: algae, medium, lipids, Scenedesmus dimorphus, nutrients

\section{INTRODUCTION}

The freshwater microalgae Scendesmus dimorphus has garnered interest as a biofuel source because of its relatively high growth rate and lipid content. Specific growth rates of $S$. dimorphus have been reported between 0.8 day $^{-1}$ [1] and $1.6 \mathrm{day}^{-1}$ (the latter for S. obliquus, a taxonomic synonym for $S$. dimonphus [2]). Lipid content in $S$. dimorphus has been reported to be between $18 \%$ and $32 \%(\mathrm{w} / \mathrm{w})[3-7]$.

While nitrogen content in the media is necessary for algae biomass production, it has been often reported that the depletion of nitrogen from the media generally causes an increase in lipid content [8] at the expense of total biomass concentration (e.g., Chlorella vulgaris $[9,10]$; Nannochloropsis sp. FEM-M24 [4]). Similar results have been obtained with some species of Scenedesmus [11], with an increase in lipid content of S. TR-84 from 20\% (in nitrogen-sufficient condition, at day 5) to $45 \%$ (in nitrogen-deficient condition, at day 14) [12], and for $S$. obliquus, $21 \%$ in nitrogen-sufficient to $46 \%$ in nitrogen-deficient conditions [13]. However, conflicting results have been obtained by others, who showed that lipid content was unaffected by nitrogen concentration, for $S$. dimorphus [3] and S. DM [4]. The type of nitrogen source also affects biomass productivity, with greater growth rates of Scenedesmus sp. $L X 1$ obtained in ammonia and urea, relative to nitrate, but with ammonia inhibiting maximum concentration because of $\mathrm{pH}$ effects [14,15].

The culture of $S$. dimorphus at the laboratory scale has often been in standard microalgae media, such as $3 \mathrm{~N}$-Basal Bold medium (3N-BB). This media contains a total of 15 chemicals, including a variety of salts, trace elements, and vitamins that have been found useful for algae growth, but not necessarily optimized for $S$. dimorphus. Given the extremely tight profit margins to be expected from largescale production of biofuel from microalgae, it is important to identify the minimally sufficient quantities of nutrients necessary to maximize lipid productivity. As has been reported with nitrogen, some nutrients have opposing effects on lipid content and biomass production for the same species. There has been much research on the effects of individual nutrients, and in some cases, ratios of nitrogen/ phosphorous, on growth of Scenedesmus [1,11,12,14-18]. However, the complexity of metabolic networks in the cell almost certainly results in interaction among the various nutrients in terms of their effects on the cell. The use of statistical experimental design techniques is an efficient method for medium design when a large number of components are involved, with potential interactions among the components. This method allows a rapid screening for the determination of optimal levels of each nutrient, as well as identification of the few components that warrant additional investigation. This approach was used by Kathiresan et al. [19] to optimize media composition for biomass, phycobiliprotein, and phycoerythrin production by the red microalgae Porphyridium purpureum. Mandal and Mallick [7] used a central composite design to determine the effect of cultivation time, nitrate, phosphate, and thiosulfate on the two outcomes of biomass concentration and lipid content of $S$. obliquus. A similar 
experimental design methodology is used here to determine the individual and interactive effects of six groupings of the components of $3 \mathrm{~N}-\mathrm{BB}$ medium on the four outcomes of biomass concentration, lipid content, growth rate, and lipid concentration for $S$. dimorpbus. The maximization of growth rate is important to minimize reactor volume (in continuous processes) or time of culture (for batch). The lipid concentration reflects the sometimes conflicting properties of lipid content and biomass concentration and is ultimately the most important outcome to be maximized. Three components were considered individually: sodium nitrate, magnesium sulfate, and calcium chloride. Monobasic and dibasic potassium phosphate were varied together as one component because of their role as a $\mathrm{pH}$ buffer. The final two components are the trace metal solution, containing five metal salts dissolved in a $\mathrm{Na}_{2}$ EDTA solution, and a vitamin solution, containing biotin, $\mathrm{B} 1$, and $\mathrm{B} 12$.

\section{MATERIALS AND METHODS}

\section{Algae Culture}

S. dimorphus was originally obtained from the UTEX culture collection (ID\# 746 Austin, TX). Algae stock was thawed from liquid nitrogen (in 5\% DMSO) and maintained in 1.5\% agar prepared with $3 \mathrm{~N}-\mathrm{BB}$ medium, containing the following components, per $1 \mathrm{~L}$ of DI water: $0.75 \mathrm{~g} \mathrm{NaNO}_{3}, 0.025 \mathrm{~g}$ $\mathrm{CaCl}_{2} \cdot 2 \mathrm{H}_{2} \mathrm{O}, 0.075 \mathrm{~g} \mathrm{MgSO}_{4} \cdot 7 \mathrm{H}_{2} \mathrm{O}, 0.075 \mathrm{~g} \mathrm{~K}_{2} \mathrm{HPO}_{4}, 0.175 \mathrm{~g}$ $\mathrm{KH}_{2} \mathrm{PO}_{4}, 0.025 \mathrm{~g} \mathrm{NaCl}, 6 \mathrm{~mL}$ trace metal stock solution (containing $0.75 \mathrm{~g} / \mathrm{L} \mathrm{Na}{ }_{2}$ EDTA, $0.097 \mathrm{~g} / \mathrm{L} \mathrm{FeCl}_{3} \cdot 6 \mathrm{H}_{2} \mathrm{O}, 0.041 \mathrm{~g} / \mathrm{L}$ $\mathrm{MnCl}_{2} \cdot 4 \mathrm{H}_{2} \mathrm{O}, 0.005 \mathrm{~g} / \mathrm{L} \mathrm{ZnCl}, 0.002 \mathrm{~g} / \mathrm{L} \mathrm{CoCl}$, and $0.004 \mathrm{~g} / \mathrm{L}$ $\mathrm{NaMoO}_{4}$ ), and $2 \mathrm{~mL}$ of each vitamin stock solution ( $\mathrm{H}$ (biotin) at $0.04 \mathrm{~g} / \mathrm{L}, \mathrm{B}_{1}$ (thiamine) at $1.105 \mathrm{~g} / \mathrm{L}$, and $\mathrm{B}_{12}$ (cyanocobalamin) at $0.1575 \mathrm{~g} / \mathrm{L}$, all in $50 \mathrm{mM}$ HEPES solution). All chemicals were from Sigma. Seed cultures for growth experiments were prepared by inoculating cells from agar into a $250 \mathrm{~mL}$ Erlenmeyer flask with $3 \mathrm{~N}-\mathrm{BB}$ medium, sparged with $5 \% \mathrm{CO}_{2}$ in air at a flow rate of 0.1 LPM, and agitated on a stir plate at room temperature. Illumination was provided by $14 \mathrm{~W}, 48^{\prime \prime}$ Accupro fluorescent bulbs on a $12 \mathrm{~h}$ on/ $12 \mathrm{~h}$ off cycle, with a measured intensity of $150-200 \mathrm{ft}$ candles at the liquid surface maintained in a sterile hood.

\section{Lipid Analysis}

Seventy-five to hundred milliliters of the algae suspension was divided into $50 \mathrm{~mL}$ centrifuge tubes and centrifuged for $1.5 \mathrm{~h}$ at $2000 \mathrm{rpm}$. The supernatant was discarded and the pellets were rinsed with DI water, vortexed, and combined in a $1.5 \mathrm{~mL}$ microcentrifuge tube, where they were centrifuged for $20 \mathrm{~min}$ at $14,000 \mathrm{rpm}$. The supernatant was discarded and the resulting pellets were dried in an oven at $45-50^{\circ} \mathrm{C}$ for $1-2$ days. The dried pellet was ground to a fine powder in mortar and pestle and transferred to a glass test tube. Five milliliters of hexane-isopropanol solution $(3: 2 \mathrm{v} / \mathrm{v}$; Acros, NJ) were added to the powdered biomass, the samples were shaken at $200 \mathrm{rpm}$ for $3 \mathrm{~h}$ on a shaker platform, and the supernatant removed. The solvent extraction procedure was repeated with $5 \mathrm{~mL}$ of fresh solvent, and after the second shaking period, the solvent was removed by filtration through $0.65-\mu \mathrm{m}$-pore filter paper (Micronsep, Honeoye, NY). The combined solvents were dried in the fume hood at room temperature and weighed to obtain the mass of the lipid fraction. These values were used to calculate lipid content $\left(y_{\mathrm{L}}, \mathrm{g}\right.$ lipid/gdw biomass).

\section{Growth Experiments}

Experiments were conducted in $250-\mathrm{mL}$ Erlenmeyer flasks with $150 \mathrm{~mL}$ working volume. Inoculum volume was determined so as to provide a starting $A_{600}$ of about 0.01 in the experimental flasks. Illumination was provided by seven 14-
W, 24" fluorescent tubes (four Coralite Aquapro T-5/10,000K and three Accupro AFL/F14T5/14W/830) on a $12 \mathrm{~h}$ on/12 h off cycle, with a measured intensity of $515-550 \mathrm{ft}$ candles at the liquid surface. Temperature and agitation control were provided by a Labline Orbital shaker bath at $30^{\circ} \mathrm{C} \pm 1{ }^{\circ} \mathrm{C}$ and $150 \mathrm{rpm}$ of agitation. Gas $\left(5 \% \mathrm{CO}_{2}\right.$ in air $\left.\mathrm{v} / \mathrm{v}\right)$ was sparged into each flask through a $200 \mu \mathrm{L}$ pipette tip at $0.1 \pm 0.02$ liters per minute. Flasks were vented through $1-\mu \mathrm{m}$ syringe filters. Each flask was sampled once daily and the absorbance at $600 \mathrm{~nm}$ measured $\left(A_{600}\right)$. Absorbance was found previously to be linear with cell concentration for $A_{600}<1.0$, with a slope of $0.62 \mathrm{gdw} / \mathrm{L}$ per $A_{6,00}$ (unpublished data). Samples with higher cell concentrations $\left(A_{6,00}>1.0\right)$ were diluted with $3 \mathrm{~N}-\mathrm{BB}$, and the absorbance reported as "adjusted absorbance."

Specific growth rates $\left(\mu\right.$, in day ${ }^{-1}$ ) were calculated from the slope of the natural $\log$ of the adjusted $A_{600}$ versus time. Biomass concentrations ( $X_{\text {final }}$, in $\mathrm{gdw} / \mathrm{L}$ ) were calculated from adjusted absorbance from the final day of the experiment.

\section{Experimental Design}

This study was performed in two experiments. The first experiment employed a two-level, six-factor fractional factorial design intended to probe the significance of media constituents on growth rate and biomass concentration. This first experiment consisted of five blocks of eight flasks each, containing a different $1 / 8$ (calculated from $1 /\left(2^{6-3}\right)$ ) fractional factorial design. Blocking was employed because the experimental set-up allowed the running of only eight flasks at a time. The six factors each consisted of one of the following components: sodium nitrate, magnesium sulfate, monobasic and dibasic potassium phosphate (varied together as one component, hereafter called potassium phosphate), calcium chloride, trace metal solution, and vitamin solution (biotin, $\mathrm{B} 1$, and B12). Monobasic and dibasic potassium phosphates were varied as a single unit in order to maintain their buffering capacity. Table 1 contains the media composition for each treatment (flask). "1" signifies that the component is at the concentration used in the $3 \mathrm{~N}-\mathrm{BB}$ medium, while a " -1 " denotes a concentration at $1 / 6$ th the level in $3 \mathrm{~N}-\mathrm{BB}$.

In the second experiment the objective was expanded to include outcomes of lipid content, in addition to growth rate and biomass concentration. The scope was narrowed by eliminating the media components found to have insignificant effects in Experiment 1. The range over which the media constituents were varied was increased to elicit a more significant cell response. The effects of four components were investigated, i.e., sodium nitrate, magnesium sulfate, potassium phosphate (monobasic and dibasic potassium phosphate varied together as one component), and calcium chloride. The experimental design was a $2^{4}$ full factorial design run in two blocks of eight flasks each. Table 3 shows the experimental compositions for each treatment. " 1 " signifies that the component is at twice the concentration used in the $3 \mathrm{~N}-\mathrm{BBM}$, while a " -1 " denotes a concentration at $1 / 10$ th the level in 3 N-BBM. Cell suspensions at the end of the experiment, on day 13 , were analyzed for lipid content as described above.

Fitted model coefficients, lower and upper confidence limits on predicted values, and $P$-values were calculated using Minitab® software.

\section{RESULTS}

\section{Experiment 1}

The specific growth rates were calculated for each flask from the adjusted absorbance measurements during the exponential growth phase. The exact period of the exponential growth phase was variable within each experiment, and the identification of this period affects the calculated growth rates. Therefore, the specific growth rates were calculated for 
Table 1. Experimental design and results from Experiment 1.

\begin{tabular}{|c|c|c|c|c|c|c|c|c|c|c|}
\hline \multirow[b]{2}{*}{ Treatment } & \multicolumn{6}{|c|}{ Component level } & \multicolumn{3}{|c|}{ Specific growth rate $\mu\left(\right.$ day $\left.^{-1}\right)$} & \multirow[b]{2}{*}{$\begin{array}{l}\text { Biomass } \\
(\mathrm{gdw} / \mathrm{L})\end{array}$} \\
\hline & $\mathrm{NaNO}_{3}$ & $\mathrm{CaCl}_{2}$ & $\mathrm{MgSO}_{4}$ & $\begin{array}{l}\text { Potassium } \\
\text { phosphates }\end{array}$ & $\begin{array}{l}\text { Trace } \\
\text { metals }\end{array}$ & Vitamins & $\begin{array}{l}\text { Growth } \\
\text { day } 4-8\end{array}$ & $\begin{array}{c}\text { Growthday } \\
4-7\end{array}$ & $\begin{array}{l}\text { Growth } \\
\text { day } 5-8\end{array}$ & \\
\hline 1 & -1 & -1 & -1 & 1 & 1 & 1 & 0.606 & 0.691 & 0.529 & 0.40 \\
\hline 2 & 1 & -1 & 1 & -1 & 1 & 1 & 0.684 & 0.770 & 0.615 & 0.39 \\
\hline 3 & -1 & 1 & 1 & 1 & -1 & 1 & 0.581 & 0.672 & 0.482 & 0.52 \\
\hline 4 & 1 & 1 & -1 & -1 & -1 & 1 & 0.589 & 0.653 & 0.523 & 0.44 \\
\hline 5 & 1 & 1 & -1 & 1 & 1 & -1 & 0.629 & 0.711 & 0.556 & 0.45 \\
\hline 6 & -1 & 1 & 1 & -1 & 1 & -1 & 0.654 & 0.735 & 0.605 & 0.47 \\
\hline 7 & 1 & -1 & 1 & 1 & -1 & -1 & 0.589 & 0.657 & 0.505 & 0.41 \\
\hline 8 & -1 & -1 & -1 & -1 & -1 & -1 & 0.656 & 0.729 & 0.610 & 0.47 \\
\hline 9 & -1 & 1 & 1 & 1 & 1 & 1 & 0.411 & 0.465 & 0.364 & 0.22 \\
\hline 10 & 1 & 1 & -1 & -1 & 1 & 1 & 0.445 & 0.487 & 0.405 & 0.26 \\
\hline 11 & -1 & -1 & -1 & 1 & -1 & 1 & 0.339 & 0.373 & 0.315 & 0.16 \\
\hline 12 & 1 & -1 & 1 & -1 & -1 & 1 & 0.468 & 0.508 & 0.431 & 0.32 \\
\hline 13 & 1 & -1 & 1 & 1 & 1 & -1 & 0.387 & 0.432 & 0.346 & 0.20 \\
\hline 14 & -1 & -1 & -1 & -1 & 1 & -1 & 0.432 & 0.475 & 0.398 & 0.29 \\
\hline 15 & 1 & 1 & -1 & 1 & -1 & -1 & 0.435 & 0.479 & 0.391 & 0.28 \\
\hline 16 & -1 & 1 & 1 & -1 & -1 & -1 & 0.492 & 0.551 & 0.449 & 0.38 \\
\hline 17 & 1 & -1 & 1 & 1 & 1 & 1 & 0.369 & 0.404 & 0.364 & 0.31 \\
\hline 18 & -1 & -1 & -1 & -1 & 1 & 1 & 0.466 & 0.506 & 0.474 & 0.41 \\
\hline 19 & 1 & 1 & -1 & 1 & -1 & 1 & 0.388 & 0.422 & 0.381 & 0.27 \\
\hline 20 & -1 & 1 & 1 & -1 & -1 & 1 & 0.422 & 0.456 & 0.427 & 0.38 \\
\hline 21 & -1 & 1 & 1 & 1 & 1 & -1 & 0.373 & 0.409 & 0.362 & 0.33 \\
\hline 22 & 1 & 1 & -1 & -1 & 1 & -1 & 0.43 & 0.468 & 0.421 & 0.40 \\
\hline 23 & -1 & -1 & -1 & 1 & -1 & -1 & 0.375 & 0.416 & 0.366 & 0.36 \\
\hline 24 & 1 & -1 & 1 & -1 & -1 & -1 & 0.431 & 0.457 & 0.430 & 0.48 \\
\hline 25 & 1 & 1 & 1 & 1 & 1 & 1 & 0.257 & 0.274 & 0.232 & 0.27 \\
\hline 26 & -1 & 1 & -1 & -1 & 1 & 1 & 0.378 & 0.400 & 0.370 & 0.44 \\
\hline 27 & 1 & -1 & -1 & 1 & -1 & 1 & 0.325 & 0.357 & 0.283 & 0.40 \\
\hline 28 & -1 & -1 & 1 & -1 & -1 & 1 & 0.379 & 0.415 & 0.350 & 0.49 \\
\hline 29 & -1 & -1 & 1 & 1 & 1 & -1 & 0.293 & 0.315 & 0.252 & 0.34 \\
\hline 30 & 1 & -1 & -1 & -1 & 1 & -1 & 0.383 & 0.405 & 0.361 & 0.54 \\
\hline 31 & -1 & 1 & -1 & 1 & -1 & -1 & 0.259 & 0.272 & 0.244 & 0.31 \\
\hline 32 & 1 & 1 & 1 & -1 & -1 & -1 & 0.334 & 0.380 & 0.303 & 0.32 \\
\hline 33 & 1 & -1 & -1 & 1 & 1 & 1 & 0.316 & 0.357 & 0.285 & 0.28 \\
\hline 34 & -1 & -1 & 1 & -1 & 1 & 1 & 0.326 & 0.349 & 0.303 & 0.35 \\
\hline 35 & 1 & 1 & 1 & 1 & -1 & 1 & 0.289 & 0.330 & 0.260 & 0.24 \\
\hline 36 & -1 & 1 & -1 & -1 & -1 & 1 & 0.339 & 0.389 & 0.290 & 0.43 \\
\hline 37 & -1 & 1 & -1 & 1 & 1 & -1 & 0.307 & 0.345 & 0.267 & 0.39 \\
\hline 38 & 1 & 1 & 1 & -1 & 1 & -1 & 0.361 & 0.417 & 0.311 & 0.41 \\
\hline 39 & -1 & -1 & 1 & 1 & -1 & -1 & 0.278 & 0.317 & 0.240 & 0.27 \\
\hline 40 & 1 & -1 & -1 & -1 & -1 & -1 & 0.359 & 0.398 & 0.326 & 0.44 \\
\hline
\end{tabular}

A component level of " 1 " indicates that the concentrations used are those in the $3 \mathrm{~N}-\mathrm{BB}$ medium; "- 1 " indicates the concentration is at $1 / 6$ th the level in the $3 \mathrm{~N}-\mathrm{BB}$ medium.

three periods of time for each experiment (days $4-7$, days $4-$ 8 , and days 5-8). The results of these calculations for Experiment 1 are shown in Table 1.

A general linear model was developed for the relationship of the growth responses to the six factors and all of their two factor interactions. Table 2 contains the model coefficients and $P$-values used to determine which of the factor or factor interactions were statistically significant. None of the interactions was found to be significant (all interaction $t$-tests using a null hypothesis of coefficient values $=0.00$ yielded $P$-values $>>0.05$ ). The model was then recalculated with only the significant first-order factor terms included, also shown in Table 2. For this reduced model, only the constant term and the coefficient for potassium phosphate $\left(\mathrm{K}_{2} \mathrm{HPO}_{4} / \mathrm{KH}_{2} \mathrm{PO}_{4}\right)$ were found to be significantly different from zero $(P<0.001)$. The final model equations for $\mu$ (specific growth rate) with all nonsignificant terms removed are:

$$
\begin{aligned}
& \mu_{\text {days } 4-7}=0.4661-0.0313 f_{\mathrm{K}_{2} \mathrm{HPO}_{4} / \mathrm{KH}_{2} \mathrm{PO}_{4}} \\
& \mu_{\text {days } 4-8}=0.4209-0.0355 f_{\mathrm{K}_{2} \mathrm{HPO}_{4} / \mathrm{KH}_{2} \mathrm{PO}_{4}} \\
& \mu_{\text {day } 5-8}=0.3857-0.0345 f_{\mathrm{K}_{2} \mathrm{HPO}_{4} / \mathrm{KH}_{2} \mathrm{PO}_{4}}
\end{aligned}
$$

where $\mu$ is in day ${ }^{-1}$, and $f_{i}$ is the coded factor for species $i$, with values between -1 and 1 , where -1 and 1 are as defined in the Experimental Design section, relative to concentrations in the $3 \mathrm{~N}-\mathrm{BB}$ medium. From Eq. 1 (plotted in Figure 1), it can be concluded that the higher level of potassium phosphate negatively affected the observed growth rates (i.e., a negative coefficient) and the other factors have no statistically significant effect on growth rate. 
Table 2. Experimental design and results from Experiment 2.

\begin{tabular}{|c|c|c|c|c|c|c|c|c|c|c|}
\hline \multirow[b]{2}{*}{ Flask } & \multicolumn{4}{|c|}{ Component level } & \multicolumn{3}{|c|}{$\begin{array}{c}\text { Specific growth rate } \\
\mu\left(\text { day }^{-1}\right)\end{array}$} & \multirow{2}{*}{$\begin{array}{l}\text { Biomass } \\
\text { day } 13 \\
(\operatorname{gdw} / \mathrm{L})\end{array}$} & \multirow{2}{*}{$\begin{array}{c}\text { Lipid } \\
\text { content day } \\
13(w t \%)\end{array}$} & \multirow{2}{*}{$\begin{array}{c}\text { Lipid } \\
\text { concentration } \\
\text { day } 13(\mathrm{~g} / \mathrm{L})\end{array}$} \\
\hline & $\mathrm{NaNO}_{3}$ & $\mathrm{CaCl}_{2}$ & $\mathrm{MgSO}_{4}$ & $\begin{array}{l}\text { Potassium } \\
\text { phosphates }\end{array}$ & $\begin{array}{c}\text { Days } \\
4-7\end{array}$ & $\begin{array}{c}\text { Days } \\
4-8\end{array}$ & $\begin{array}{c}\text { Days } \\
5-8\end{array}$ & & & \\
\hline 1 & -1 & -1 & 1 & -1 & 0.43 & 0.54 & 0.35 & 0.89 & 16.9 & 0.15 \\
\hline 2 & 1 & -1 & 1 & 1 & 0.49 & 0.58 & 0.43 & 1.80 & 2.60 & 0.05 \\
\hline 3 & -1 & -1 & -1 & 1 & 0.40 & 0.49 & 0.34 & 0.87 & 15.5 & 0.14 \\
\hline 4 & -1 & 1 & 1 & 1 & 0.41 & 0.52 & 0.32 & 0.98 & 11.5 & 0.12 \\
\hline 5 & 1 & -1 & -1 & -1 & 0.40 & 0.49 & 0.32 & 1.04 & 10.3 & 0.09 \\
\hline 6 & -1 & 1 & -1 & -1 & 0.41 & 0.51 & 0.32 & 0.97 & 20.5 & 0.20 \\
\hline 7 & 1 & 1 & -1 & 1 & 0.40 & 0.51 & 0.34 & 0.84 & 10.0 & 0.08 \\
\hline 8 & 1 & 1 & 1 & -1 & 0.46 & 0.55 & 0.39 & 1.61 & 2.20 & 0.04 \\
\hline 9 & -1 & 1 & -1 & 1 & 0.46 & 0.49 & 0.42 & 0.91 & 28.0 & 0.27 \\
\hline 10 & 1 & -1 & 1 & -1 & 0.45 & 0.50 & 0.38 & 1.71 & 8.80 & 0.01 \\
\hline 11 & -1 & -1 & 1 & 1 & 0.38 & 0.44 & 0.31 & 0.85 & 26.8 & 0.25 \\
\hline 12 & -1 & -1 & -1 & -1 & 0.43 & 0.44 & 0.41 & 0.63 & 21.3 & 0.13 \\
\hline 13 & 1 & 1 & -1 & -1 & 0.46 & 0.53 & 0.38 & 1.08 & 8.00 & 0.10 \\
\hline 14 & 1 & 1 & 1 & 1 & 0.46 & 0.51 & 0.41 & 1.34 & 7.10 & 0.09 \\
\hline 15 & 1 & -1 & -1 & 1 & 0.42 & 0.41 & 0.45 & 0.71 & 7.70 & 0.06 \\
\hline 16 & -1 & 1 & 1 & -1 & 0.52 & 0.55 & 0.49 & 0.80 & 27.6 & 0.23 \\
\hline
\end{tabular}

" 1 " denotes that the component is at a concentration that is $2 \times$ that of $3 \mathrm{~N}-\mathrm{BB}$; " -1 " denotes that the component is at a concentration that is $1 / 10$ that of $3 \mathrm{~N}-\mathrm{BB}$.

The regression model was also employed to fit an equation using the final biomass concentration from this experiment (at day 9) as the response. The first calculation utilized all six factors as well as all possible two-factor interactions. From this calculation the only significant factor coefficients found were those for potassium phosphate $(P=0.001)$ and the $\mathrm{NaNO}_{3} \cdot \mathrm{CaCl}_{2}$ interaction $(P=0.043)$, as shown in Table 2. All others were found to be nonsignificant $(P>0.18)$. A second model was then fitted using the significant terms as well as terms for the first-order $\mathrm{NaNO}_{3}$ and $\mathrm{CaCl}_{2}$ factors included to satisfy model hierarchy requirements. This second calculation produced the following reduced model:

$$
\begin{aligned}
X_{\text {final }} & =0.3621-0.0424 f_{\mathrm{K}_{2} \mathrm{HPO}_{4} / \mathrm{KH}_{2} \mathrm{PO}_{4}}-0.0087 . f_{\mathrm{NaNO}_{3}} \\
& -0.0026 f_{\mathrm{CaCl}_{2}}-0.0187 f_{\mathrm{NaNO}_{3}} f_{\mathrm{CaCl}_{2}}
\end{aligned}
$$

Analysis of this model predicts that the lowest biomass concentration will occur with all three of these factors at their highest (i.e., 3N-BB) levels (Figure 2a). Because of the interaction term in Eq. 2, the highest predicted biomass yields occur when potassium phosphate and sodium nitrate are at their lowest levels and $\mathrm{CaCl}_{2}$ at its highest (Figure $2 \mathrm{a}$ ). The predicted value for $X_{\text {final }}$ for this case, as shown in Table $5\left(X_{\text {final }}=0.43 \mathrm{gdw} / \mathrm{L}\right)$, is significantly greater than that for the $3 \mathrm{~N}-\mathrm{BB}$ levels $\left(X_{\mathrm{final}}=0.29 \mathrm{gdw} / \mathrm{L}\right)$, as evidenced by the absence of overlap of the $95 \%$ confidence intervals. The predicted biomass concentration for the case of all three factors at their lowest value $\left(X_{\text {final }}=0.40 \mathrm{gdw} / \mathrm{L}\right)$ is close to the highest predicted yield and not significantly different from it, but is significantly greater than that for the $3 \mathrm{~N}-\mathrm{BB}$ case (from comparison of confidence intervals).

In summary, these results suggest that all six components could be reduced to $1 / 6$ th the value in the $3 \mathrm{~N}-\mathrm{BB}$ with a significant increase in biomass concentration and without a significant negative effect on growth rate.

\section{Experiment 2}

The growth curves of both blocks in Experiment 2 are shown in Figure 3. Specific growth rates were calculated over three windows of time from these curves for days 4 7 , days $4-8$, and days $5-8$ (Table 3 ). The final biomass concentrations, lipid contents, and lipid concentrations (all at day 13) are also shown in Table 3 . Regression models were fit using this data for the six responses against the four factors and all of their possible two factor interactions (Table 4).

From inspection of the $P$-values in Table 4 , none of the medium components show significant effect on the growth rates calculated from the various time intervals. On the other hand, the complete model for the biomass response contained both significant and insignificant terms. A reduced model was calculated containing significant terms (as well as first-order terms to satisfy hierarchy requirements for significant interactions):

$$
\begin{aligned}
X_{\mathrm{final}} & =1.0644-0.0269 f_{\mathrm{K}_{2} \mathrm{HPO}_{4} / \mathrm{KH}_{2} \mathrm{PO}_{4}}+0.2019 f_{\mathrm{NaNO}_{3}}+0.0019 f_{\mathrm{CaCl}_{2}} \\
& +0.1831 f_{\mathrm{MgSO}_{4}}-0.0506 f_{\mathrm{NaNO}_{3}} J_{\mathrm{CaCl}_{2}}+0.1656 f_{\mathrm{NaNO}_{3}} . f_{\mathrm{MgSO}_{4}} \\
& -0.0669 f_{\mathrm{NaNO}_{3}} f_{\mathrm{K}_{2} \mathrm{HPO}_{4} / \mathrm{KH}_{2} \mathrm{PO}_{4}}-0.0669 \mathrm{CaCl}_{2}, f_{\mathrm{MgSO}_{4}}
\end{aligned}
$$

The large number of two-way interactions can be visualized using the interaction plots shown in Figure 4 . These plots show that at low concentration, sodium nitrate dominates, inhibiting the effects of the other components and producing relatively low biomass yields (Figures $4 a-4 c$ ). With sodium nitrate at its high concentration level, magnesium sulfate has a relatively large effect producing higher biomass yields at its high level (Figure 4b). With either sodium nitrate or magnesium sulfate at their high levels, calcium chloride produces higher biomass yields at its low level (Figures $4 \mathrm{a}$ and $4 \mathrm{~d}$ ). These observations likely result from the needs for nitrogen for protein synthesis, the major component of growing cells. $\mathrm{Ca}^{++}$and $\mathrm{Mg}^{++}$ions are important cofactors in many enzymes of the intermediary metabolism, which may account for the interactions of these two components.

Regression was also employed to fit both full and reduced models to the lipid data (Table 4). The only significant factor 
affecting the values of both lipid content ( $y_{1}$, in $\mathrm{g}$ lipid/gdw biomass $)$ and lipid concentration $\left(L_{\mathrm{final}}\right.$, in $\left.\mathrm{g} / \mathrm{L}\right)$ was sodium nitrate. The reduced model equations are:

$y_{\mathrm{L}}=0.1405-0.0696 f_{\mathrm{NaNO}_{3}}$

$L_{\text {final }}=0.1309-0.0484 f_{\mathrm{NaNO}_{3}}$

High levels of nitrate, which promote increases in biomass concentration, also inhibit lipid accumulation (Figure $5)$, as shown by the $P^{2}$-value of 0.000 for the model coefficient of -0.0696 (Table 4). In fact, $\mathrm{NaNO}_{3}$ is the only component that significantly affects lipid content in these results The final lipid concentration in the flask, which is calculated from the product of the lipid content and final biomass concentration, is, not surprisingly, significantly affected only by $\mathrm{NaNO}_{3}$, with an overall negative effect.

\section{DISCUSSION}

Much of the lab-scale research on algae growth uses general algae medium formulations, such as $3 \mathrm{~N}-\mathrm{BB}$, which have been developed over time and found to support a variety of algae genus and species. While the medium is relatively inexpensive to prepare for laboratory research, costs for medium constituents can make or break large-scale algae

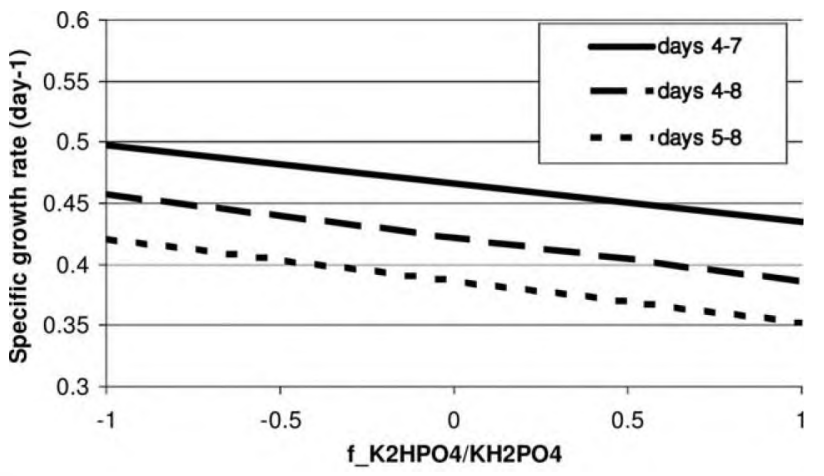

Figure 1. Effect of $\mathrm{K}_{2} \mathrm{HPO}_{4} \cdot \mathrm{KH}_{2} \mathrm{PO}_{4}$ on specific growth rate, from Eq. 1 using Experiment 1 data. The abscissa represents

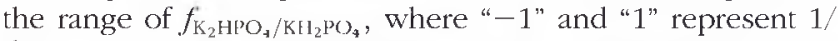
th and $1 \times$, respectively, the concentration of $\mathrm{K}_{2} \mathrm{HPO}_{4} \mathrm{KH}_{2} \mathrm{PO}_{4}$ in $3 \mathrm{~N}-\mathrm{BB}$ medium. culture for commodity products such as fuel. The objective of this research is to determine the minimal nutrient concentrations necessary to achieve maximal algae growth and lipid productivity. The motivation is not only to make algae oil production economically feasible, but environmentally sound as well. The six major groupings of medium constituents were screened in the first phase of this research to identify those which most influenced biomass productivity. The investigation of medium components was then broadened to include effects on lipid content and biomass concentration in early stationary phase, in addition to growth rate. The focus was narrowed to the four major salts, while the range of concentrations was expanded, to a 20 -fold variation.

\section{Growth Rate}

A high growth rate is crucial for biomass production in industrial scale processes in order to reduce the capital equipment (for continuous processes) and land costs. The finding that all the tested media components could be reduced to $1 / 6$ the level in the $3 \mathrm{~N}-\mathrm{BB}$ medium without influencing growth rate or final biomass concentration is a positive one, and can significantly reduce nutrient costs at the large scale. The only exception was potassium phosphate, in which lower concentrations actually yielded higher growth rates (Eq. 1). This is significant given that phosphate fertilizers have more than doubled in cost between 2005 and 2011 [20] making it the single most expensive macronutrient. Statistical analysis of the data shows that using $1 / 6$ the level of potassium phosphates used in $3 \mathrm{~N}-\mathrm{BB}$ in fact boosts the growth rate of $S$. dimorphus anywhere from $8 \%$ to $66 \%$ (at $95 \%$ confidence), as determined from the model in Eq. 1. These experiments could not distinguish whether this effect is due to the $\mathrm{K}^{+}$or $\mathrm{PO}_{4}{ }^{3-}$ ions. However, since it has been shown that excess phosphorus competes with iron and manganese uptake by plants [21], both of which are essential nutrients in plants $[22,23]$, it is more likely that the phosphate ions are the inhibitory substances. Further investigation using other phosphate salts and potassium salts may resolve this question. The negative effect of the potassium phosphates on growth rate was not corroborated in the second experiment. This may result from nonlinearity in the response curve, i.e., the growth rate may increase at $1 / 6$ the $3 \mathrm{~N}-\mathrm{BB}$ concentration, but then decrease to basal growth rate at $1 / 10$ the concentration. At this lowest potassium phosphate concentration, the phosphorous may no longer compete with the iron or manganese. The lack of a phosphorous effect on (a) Highest potassium phosphate level

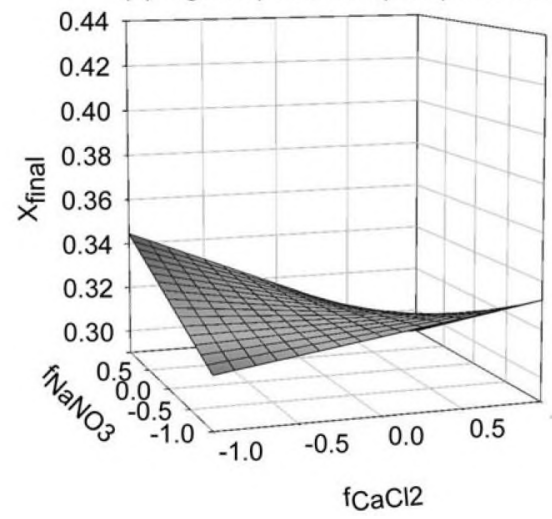

(b) Lowest potassium phosphate level

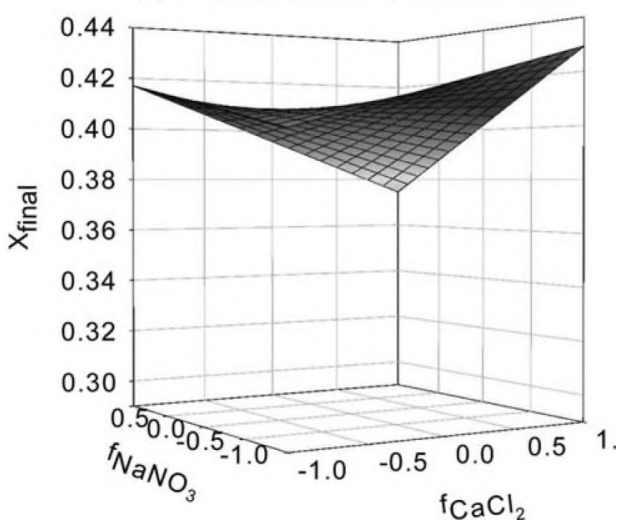

Figure 2. Effects of interactions of $\mathrm{NaNO}_{3}$ and $\mathrm{CaCl}_{2}$ on biomass concentration, using Eq. 2 developed from Experiment 1 data. The abscissas represent the range of the factors, where " -1 " and " 1 " represent $1 / 6$ th and $1 \times$, respectively, the concentration of that factor in $3 \mathrm{~N}-\mathrm{BB}$ medium. The ordinate represents the biomass concentration, in gdw/L. (a) Calculated using $f_{\mathrm{K}_{2} \mathrm{HPO}_{4} / \mathrm{KH}_{2} \mathrm{PO}_{4}}=1$ for minimum biomass; (b) Calculated using $f_{\mathrm{K}_{2} \mathrm{HPO}_{4} / \mathrm{KH}_{2} \mathrm{PO}_{4}}=-1$ for maximum biomass. 
Table 3. Model results from Experiment 1 data.

\begin{tabular}{|c|c|c|c|c|c|c|c|c|}
\hline \multirow[b]{2}{*}{ Factor } & \multicolumn{2}{|c|}{ н Days 4-7 } & \multicolumn{2}{|c|}{ ب Days 4-8 } & \multicolumn{2}{|c|}{$\mu$ Days 5-8 } & \multicolumn{2}{|c|}{$\begin{array}{c}\text { Biomass } \\
\text { concentration }\end{array}$} \\
\hline & $\begin{array}{l}\text { Regression } \\
\text { coefficient }\end{array}$ & $P$-value* & $\begin{array}{l}\text { Regression } \\
\text { coefficient }\end{array}$ & $P$-value & $\begin{array}{l}\text { Regression } \\
\text { coefficient }\end{array}$ & $P$-value & $\begin{array}{l}\text { Regression } \\
\text { coefficient }\end{array}$ & $P$-value \\
\hline \multicolumn{9}{|c|}{ Regression coefficients, including all factors and their second-order interactions } \\
\hline Constant & 0.4661 & 0.000 & 0.4209 & 0.000 & 0.3857 & 0.000 & 0.3621 & 0.000 \\
\hline $\mathrm{NaNO}_{3}$ & 0.0038 & 0.588 & 0.0038 & 0.489 & 0.0020 & 0.674 & -0.0094 & 0.373 \\
\hline $\mathrm{CaCl}_{2}$ & -0.001 & 0.879 & -0.0027 & 0.585 & -0.0034 & 0.449 & -0.0070 & 0.469 \\
\hline $\mathrm{MgSO}_{4}$ & -0.0017 & 0.791 & -0.0031 & 0.540 & -0.0051 & 0.265 & -0.0129 & 0.194 \\
\hline Potassium phosphates & -0.0294 & 0.000 & -0.0291 & 0.000 & -0.0336 & 0.000 & -0.0376 & 0.001 \\
\hline Trace metals & 0.0046 & 0.512 & 0.0049 & 0.365 & 0.0062 & 0.213 & -0.0060 & 0.569 \\
\hline Vitamins & -0.0032 & 0.621 & -0.0029 & 0.563 & -0.0028 & 0.537 & -0.0133 & 0.181 \\
\hline $\mathrm{NaNO}_{3}{ }^{*} \mathrm{CaCl}_{2}$ & -0.0062 & 0.349 & -0.0062 & 0.222 & -0.0059 & 0.201 & -0.0211 & 0.043 \\
\hline $\mathrm{NaNO}_{3}{ }^{*} \mathrm{MgSO}_{4}$ & -0.0056 & 0.390 & -0.0057 & 0.262 & -0.0043 & 0.344 & -0.0127 & 0.200 \\
\hline $\mathrm{NaNO}_{3}{ }^{*}$ Phosphates & 0.0062 & 0.349 & 0.0065 & 0.202 & 0.0095 & 0.048 & 0.0025 & 0.795 \\
\hline $\mathrm{NaNO}_{3}{ }^{*}$ trace metals & 0.0011 & 0.879 & -0.0003 & 0.954 & -0.0006 & 0.902 & 0.0034 & 0.741 \\
\hline $\mathrm{NaNO}_{3}{ }^{*}$ Vitamins & -0.0026 & 0.688 & -0.0014 & 0.776 & 0.0007 & 0.884 & -0.0134 & 0.178 \\
\hline $\mathrm{CaCl}_{2}{ }^{*} \mathrm{MgSO}_{4}$ & 0.0059 & 0.496 & 0.0032 & 0.633 & 0.0035 & 0.558 & -0.0008 & 0.949 \\
\hline $\mathrm{CaCl}_{2}{ }^{*}$ phosphates & 0.005 & 0.562 & 0.0058 & 0.389 & 0.0068 & 0.258 & 0.0081 & 0.530 \\
\hline $\mathrm{CaCl}_{2}{ }^{*}$ trace metals & 0.0013 & 0.836 & 0.0021 & 0.677 & 0.0031 & 0.484 & 0.0061 & 0.530 \\
\hline $\mathrm{CaCl}_{2}{ }^{*}$ vitamins & -0.0048 & 0.576 & -0.0028 & 0.673 & -0.0023 & 0.703 & -0.0015 & 0.906 \\
\hline $\mathrm{MgSO}_{4}$ "phosphates & -0.0049 & 0.566 & -0.0050 & 0.455 & -0.0063 & 0.296 & 0.0013 & 0.920 \\
\hline $\mathrm{MgSO}_{4}{ }^{*}$ trace metals & -0.0069 & 0.299 & -0.0098 & 0.280 & -0.0098 & 0.280 & -0.0102 & 0.297 \\
\hline $\mathrm{MgSO}_{4}{ }^{*}$ vitamins & -0.0023 & 0.787 & -0.0024 & 0.836 & -0.0024 & 0.836 & 0.0031 & 0.806 \\
\hline Phosphates*trace metals & -0.0001 & 0.989 & -0.0020 & 0.821 & -0.0020 & 0.821 & 0.0011 & 0.909 \\
\hline Phosphates*vitamins & -0.0024 & 0.776 & -0.0054 & 0.649 & -0.0054 & 0.649 & 0.0026 & 0.836 \\
\hline Trace metals*vitamins & 0.0027 & 0.674 & 0.0096 & 0.293 & 0.0096 & 0.293 & -0.0097 & 0.323 \\
\hline \multicolumn{9}{|c|}{ Regression coefficients for model reduced to significant terms } \\
\hline Constant & 0.4661 & 0.000 & 0.4209 & 0.000 & 0.3857 & 0.000 & 0.3621 & 0.000 \\
\hline $\mathrm{NaNO}_{3}{ }^{* *}$ & $\mathrm{~N} / \mathrm{A}$ & $\mathrm{N} / \mathrm{A}$ & $\mathrm{N} / \mathrm{A}$ & $\mathrm{N} / \mathrm{A}$ & $\mathrm{N} / \mathrm{A}$ & $\mathrm{N} / \mathrm{A}$ & -0.0087 & 0.320 \\
\hline $\mathrm{CaCl}_{2}{ }^{* *}$ & $\mathrm{~N} / \mathrm{A}$ & $\mathrm{N} / \mathrm{A}$ & $\mathrm{N} / \mathrm{A}$ & $\mathrm{N} / \mathrm{A}$ & $\mathrm{N} / \mathrm{A}$ & $\mathrm{N} / \mathrm{A}$ & -0.0026 & 0.769 \\
\hline Phosphates & -0.0313 & 0.000 & -0.0355 & 0.000 & -0.0345 & 0.000 & -0.0424 & 0.000 \\
\hline $\mathrm{NaNO}_{3}{ }^{*} \mathrm{CaCl}_{2}$ & $\mathrm{~N} / \mathrm{A}$ & $\mathrm{N} / \mathrm{A}$ & $\mathrm{N} / \mathrm{A}$ & $\mathrm{N} / \mathrm{A}$ & $\mathrm{N} / \mathrm{A}$ & $\mathrm{N} / \mathrm{A}$ & -0.0187 & 0.038 \\
\hline
\end{tabular}

Statistically significant results are in bold italics.

* $P$ values for $t$-test HO: Factor coefficient $=0.0$; HA: Factor coefficient $<>0.0$.

** Because the $\mathrm{NaNO}_{3}{ }^{*} \mathrm{CaCl}_{2}$ interaction is significant for biomass, the first-order terms have been included to satisfy model hierarchial requirements.
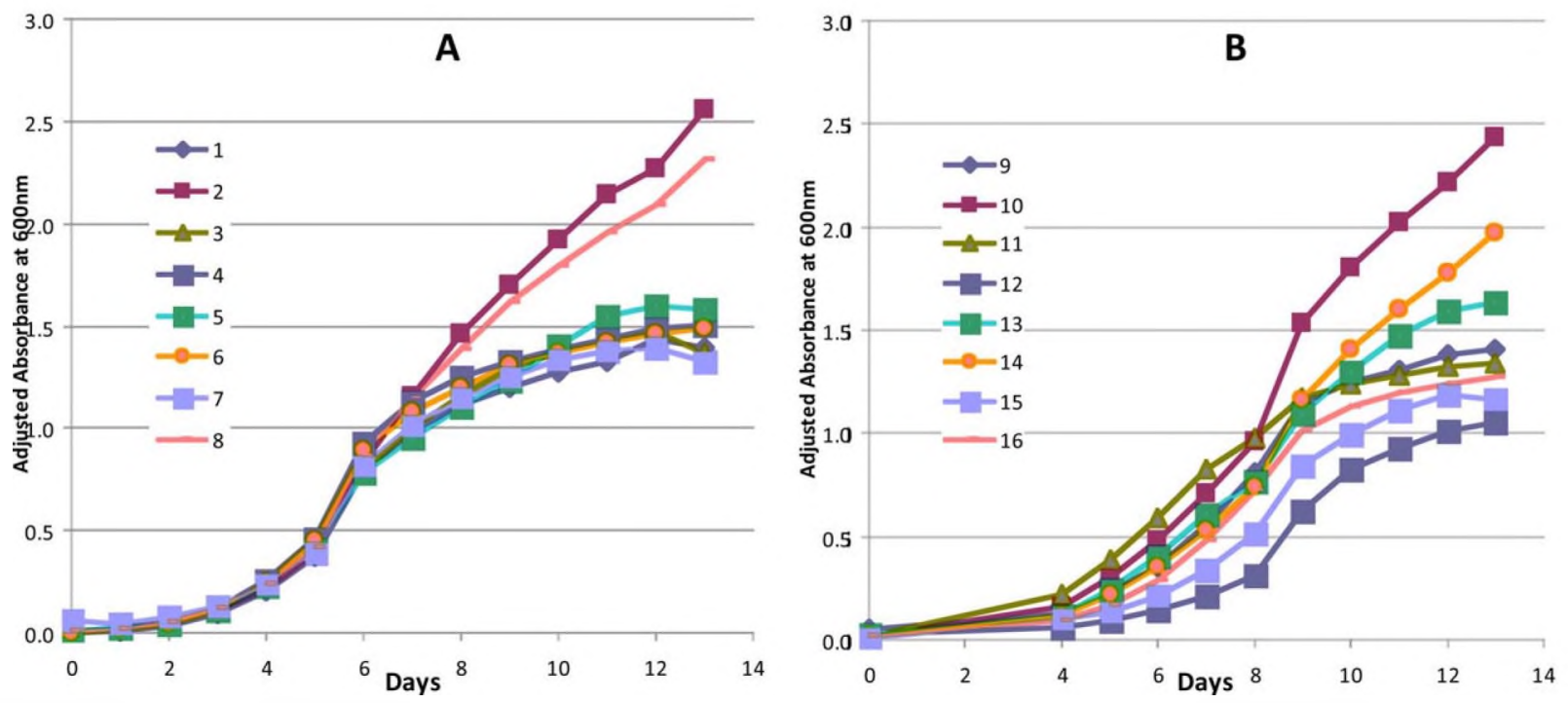

Figure 3. Growth curves from Experiment 2. (a) Treatments 1-8 in block 1; (b) Treatments 9-16 in block 2. Media compositions for each flask are given in Table 3. [Color figure can be viewed in the online issue, which is available at wileyonlinelibrary.com.] 
Table 4. Predicted biomass concentration and 95\% confidence limits, as calculated from Eq. 2, derived from Experiment 1 data.

\begin{tabular}{|c|c|c|c|c|c|}
\hline$f_{\mathrm{NaNO}}$ & $f_{\mathrm{CaCl2}}$ & $f_{\text {potassium phosphate }}$ & $\begin{array}{l}\text { Predicted biomass } \\
\text { concentration } \\
(\mathrm{gdw} / \mathrm{L}), \boldsymbol{X}_{\mathrm{final}}\end{array}$ & $\begin{array}{c}95 \% \text { lower } \\
\text { confidence limit }\end{array}$ & $\begin{array}{c}95 \% \text { upper } \\
\text { confidence limit }\end{array}$ \\
\hline-1 & 1 & -1 & 0.429 & 0.390 & 0.469 \\
\hline-1 & -1 & -1 & 0.397 & 0.358 & 0.436 \\
\hline 1 & 1 & 1 & 0.290 & 0.250 & 0.329 \\
\hline
\end{tabular}

" -1 " refers to concentrations at $1 / 6$ that of $3 \mathrm{~N}-\mathrm{BB}$; " 1 " refers to concentrations equal to that of $3 \mathrm{~N}-\mathrm{BB}$.

Table 5. Model results from Experiment 2 data

\begin{tabular}{|c|c|c|c|c|c|c|c|c|c|}
\hline \multirow[b]{2}{*}{ Model term } & \multirow{2}{*}{$\begin{array}{c}\mu \text { Days } \\
4-7 \\
P \text {-value }\end{array}$} & \multirow{2}{*}{$\begin{array}{c}\mu \text { Days } \\
4-8 \\
P \text {-value }\end{array}$} & \multirow{2}{*}{$\begin{array}{c}\mu \text { Days } \\
5-8 \\
P \text {-value }\end{array}$} & \multicolumn{2}{|c|}{ Biomass } & \multicolumn{2}{|c|}{ Lipid content } & \multicolumn{2}{|c|}{ Lipid concentration } \\
\hline & & & & $\begin{array}{l}\text { Regression } \\
\text { coefficient }\end{array}$ & $P$-value & $\begin{array}{l}\text { Regression } \\
\text { coefficient }\end{array}$ & $P$-value & $\begin{array}{l}\text { Regression } \\
\text { coefficient }\end{array}$ & $P$-value \\
\hline \multicolumn{10}{|c|}{ Regression coefficients, including all factors and their second-order interactions } \\
\hline Constant & 0.000 & 0.000 & 0.000 & 1.0644 & 0.000 & 0.1405 & 0.001 & 0.1309 & 0.001 \\
\hline Block & 0.352 & 0.148 & 0.083 & 0.0606 & 0.034 & -0.0286 & 0.119 & -0.0221 & 0.159 \\
\hline $\mathrm{NaNO}_{3}$ & 0.590 & 0.605 & 0.504 & 0.2019 & 0.000 & -0.0696 & 0.009 & -0.0484 & 0.019 \\
\hline $\mathrm{CaCl}_{2}$ & 0.352 & 0.192 & 0.697 & 0.0019 & 0.927 & 0.0031 & 0.839 & 0.0051 & 0.710 \\
\hline $\mathrm{MgSO}_{4}$ & 0.267 & 0.148 & 0.628 & 0.1831 & 0.001 & -0.0111 & 0.484 & -0.0010 & 0.944 \\
\hline Potassium phosphates & 0.459 & 0.421 & 0.922 & -0.0269 & 0.234 & -0.0040 & 0.796 & -0.0046 & 0.740 \\
\hline $\mathrm{NaNO}_{3}{ }^{*} \mathrm{CaCl}_{2}$ & 0.459 & 0.834 & 0.354 & -0.0506 & 0.058 & -0.0058 & 0.711 & -0.0124 & 0.388 \\
\hline $\mathrm{NaNO}_{3}{ }^{*} \mathrm{MgSO}_{4}$ & 0.459 & 0.677 & 0.504 & 0.1656 & 0.001 & -0.0080 & 0.609 & 0.0004 & 0.976 \\
\hline $\mathrm{NaNO}_{3}{ }^{*}$ phosphates & 0.459 & 0.834 & 0.150 & -0.0669 & 0.025 & 0.0016 & 0.916 & -0.0078 & 0.575 \\
\hline $\mathrm{CaCl}_{2}{ }^{*} \mathrm{MgSO}_{4}$ & 0.912 & 0.477 & 0.354 & -0.0669 & 0.025 & -0.0115 & 0.470 & -0.0190 & 0.211 \\
\hline $\mathrm{CaCl}_{2}{ }^{*}$ phosphates & 0.590 & 0.754 & 0.449 & -0.0219 & 0.318 & 0.0019 & 0.903 & 0.0052 & 0.705 \\
\hline $\mathrm{MgSO}_{4}{ }^{*}$ phosphates & 0.590 & 0.916 & 0.245 & 0.0219 & 0.318 & -0.0054 & 0.729 & -0.0048 & 0.728 \\
\hline
\end{tabular}

Biomass

Regression coefficient
Lipid content

\begin{tabular}{|c|c|c|c|}
\hline Model term & $\begin{array}{l}\text { Regression } \\
\text { coefficient }\end{array}$ & $P$-value & $\begin{array}{l}\text { Regression } \\
\text { coefficien }\end{array}$ \\
\hline \multicolumn{4}{|c|}{ Model data from regression - Model reduced to significant terms } \\
\hline Constant & 1.0644 & 0.000 & 0.1405 \\
\hline $\mathrm{NaNO}_{3}$ & 0.2019 & 0.000 & -0.069 \\
\hline $\mathrm{CaCl}_{2}^{* *}$ & 0.0019 & 0.929 & \\
\hline $\mathrm{MgSO}_{4}$ & 0.1831 & 0.000 & \\
\hline Potassium phosphates** & -0.0269 & 0.230 & \\
\hline $\mathrm{NaNO}_{3}{ }^{*} \mathrm{CaCl}_{2}$ & -0.0506 & 0.046 & \\
\hline $\mathrm{NaNO}_{3}{ }^{*} \mathrm{MgSO}_{4}$ & 0.1656 & 0.000 & \\
\hline $\mathrm{NaNO}_{3}{ }^{*}$ phosphates & -0.0669 & 0.016 & \\
\hline $\mathrm{CaCl}_{2} * \mathrm{MgSO}_{4}$ & -0.0669 & 0.016 & \\
\hline
\end{tabular}

Lipid concentration

\begin{tabular}{ll}
\hline Regression & \\
coefficient & $P$-value
\end{tabular}

$P$-value coefficient

$P$-value

Statistically significant results are in bold italics. Blank entries for regression coefficients in reduced model indicate insignificant terms.

${ }^{*} P$ values for $t$-test HO: Factor coefficient $=0.0$; HA: Factor coefficient $<>0.0$.

** Nonsignificant first-order terms have been included in the reduced model when they also appear in interactions to satisfy model hierarchy requirements.

growth rate at $1 / 103 \mathrm{~N}-\mathrm{BB}$ concentration, corresponding to $5.3 \mathrm{mg} \mathrm{P} / \mathrm{L}$, is corroborated by the very low reported value for $K \mathrm{~s}$ for phosphorous: $0.27 \mathrm{mg} \mathrm{P} / \mathrm{L}$ [24]. On the other hand, the concentration of nitrogen at $1 / 103 \mathrm{~N}-\mathrm{BB}$ levels is $12 \mathrm{mg} / \mathrm{L}$, which is identical to the reported $\mathrm{Ks}$ for nitrogen [17]. Although we did not observe any effect of vitamin levels $\left(B_{1}\right.$ and $\left.B_{12}\right)$ on growth rate, it has been shown that vitamins $B_{6}$ and $B_{2}$ assist algae in response to stress by heavy metals [25].

The calculated growth rates are functions of the specific window of time considered to be "exponential phase." To ensure that the potential subjectivity in indentifying the exponential phase, and the subsequent variation in specific growth rate calculations, did not influence the conclusions, the statistical analyses were conducted using specific growth rates calculated for three different windows of time. In all cases, the same conclusions with regard to media component effects on growth rate were obtained.

\section{Biomass Concentration}

The second experiment showed that higher biomass yields resulted from those cultures supplemented with 


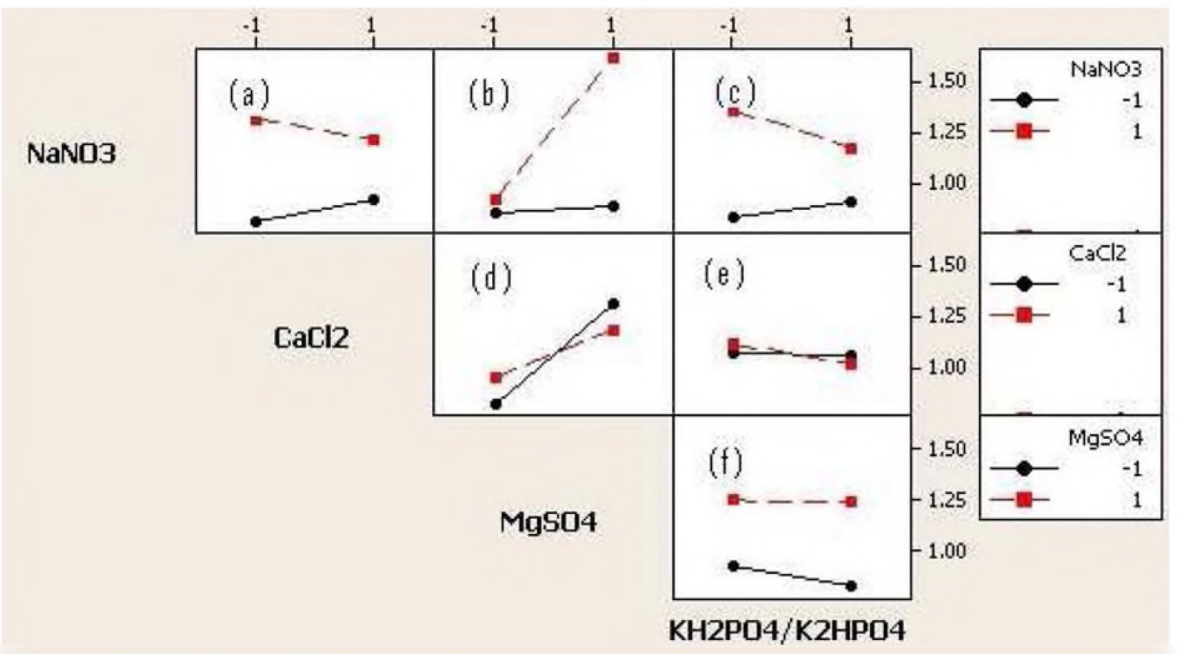

Figure 4. Effects of interactions of the four factors from Experiment 2 on biomass concentration. The abscissas represent the range of the factors, where " -1 " and " +1 " represent $1 / 10 \times$ and $2 \times$ the concentration of that factor relative to the $3 \mathrm{~N}-\mathrm{BBM}$.

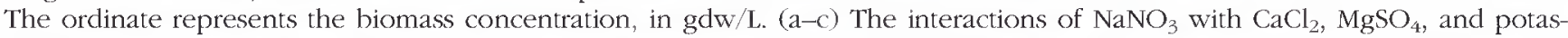
sium phosphates, respectively. ( $\mathrm{d}$ and e) The interactions of $\mathrm{CaCl}_{2}$ with $\mathrm{MgSO}_{4}$ and potassium phosphates, respectively. (f) The interaction of $\mathrm{MgSO}_{4}$ and potassium phosphates. [Color figure can be viewed in the online issue, which is available at wileyonlinelibrary.com.]

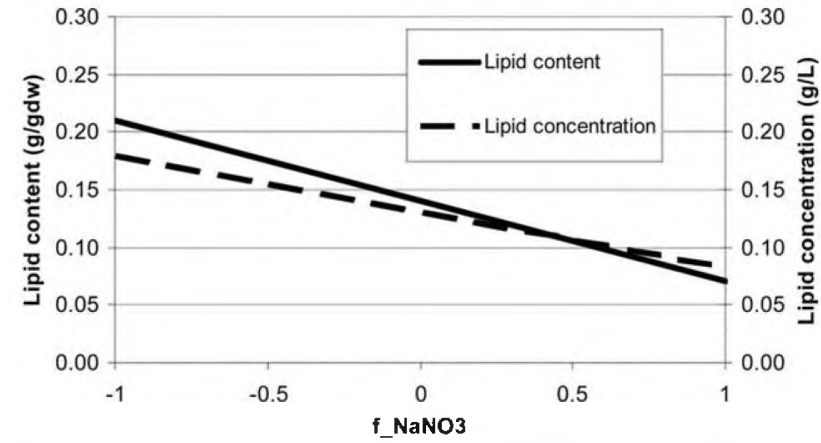

Figure 5. Effect of $\mathrm{NaNO}_{3}$ on lipid content and lipid concentration, from Eqs. 4 and 5, respectively, using Experiment 2 data. The abscissa represents the range of $f_{\mathrm{NaNO}_{3}}$ where " -1 " and " 1 " represent $1 / 10$ th and $2 \times$, respectively, the concentration of $\mathrm{NaNO}_{3}$ in $3 \mathrm{~N}-\mathrm{BB}$ medium.

excess $\mathrm{NaNO}_{3}$ and $\mathrm{MgSO}_{4}$, separately and in combination It is not surprising that these two chemicals are limiting for biomass concentration, given that nitrogen is essential for protein synthesis and magnesium is an essential component in the reaction center of chloroplasts. The concurrent excess of these two components exhibits a synergistic effect on biomass by allowing cultures to maintain active cell division throughout the 13-day study period. Low levels of these components do not seem to have an effect on growth rate per se, but rather force an early stationary phase due to nutrient depletion, which reduces the final biomass concentration (Figure 4b). This effect was not observed in the first set of experiments (Table 3), in which the experiments were only carried out to day 9, and thus many of the cultures did not reach stationary phase, and nutrients may not yet have been depleted. Biomass concentration was unaffected by either reduced $(1 / 6)$ or enhanced $(2 \times)$ levels of trace metals, consistent with a previous environmental study using $\mathrm{CoCl}_{2}$ [25].

\section{Lipid Yield}

There is ample evidence in the literature that higher levels of lipid accumulation occur during periods of stress, when active replication is halted or slowed by nitrogen limitation, both in a variety of algae genus [8] and the Scendesmus genus $[12,13]$. Our data supports this conjecture as well, showing that low levels of $\mathrm{NaNO}_{3}$ led to higher cellular lipid content, up to $28 \%$ by dry weight, while excess $\mathrm{NaNO}_{3}$, in combination with excess of other nutrients, results in lipid content as low as $2.2 \%$ (Table 3). Equation 4 suggests maximum lipid content occurs with the minimum $\mathrm{NaNO}_{3}$ concentration tested here, which is equivalent to $0.055 \mathrm{~g} \mathrm{NO}_{3}^{-} / \mathrm{L}$. This confirms previous results showing that $0.04 \mathrm{~g} \mathrm{NO}_{3}{ }^{-} / \mathrm{L}$ was optimal for lipid content for $S$. obliquus [7]. Limitations in light and/or $\mathrm{CO}_{2}$ may have caused the absence of this observed effect of nitrogen on lipid accumulation for $S$. dimorphus from several other reports in the literature $[3,4]$. We did not observe a significant effect of the potassium phosphates on lipid content, over the range of concentrations evaluated here $\left(0.02,0.16\right.$, and $\left.0.32 \mathrm{~g} \mathrm{PO}_{4}^{3-}\right)$ $\mathrm{L}$ ), whereas an optimum has been reported at the low end of this range, at $0.03 \mathrm{~g} \mathrm{PO}_{4}^{3-} / \mathrm{L}$ [7].

The actual lipid productivity of the cultures is indicated by the final lipid concentration, and optimal media composition must take into account the trade-offs associated between the constituents of this property, i.e., lipid content and biomass concentration. Of the four components tested explicitly $\left(\mathrm{NaNO}_{3}, \mathrm{CaCl}_{2}, \mathrm{MgSO}_{4}\right.$, and $\mathrm{K}_{2} \mathrm{HPO}_{4} / \mathrm{KH}_{2} \mathrm{PO}_{4}$ ), only $\mathrm{NaNO}_{3}$ affected the lipid concentration over the 20 -fold variation in concentrations tested here. The small negative coefficient for $\mathrm{NaNO}_{3}(-0.048$, Eq. 4) indicates that the effect on lipid content slightly outweighs the effect on biomass concentration. The final lipid yield is not the only important productivity metric; the time to reach this (i.e., the growth rate) also strongly influences the process economics. Given that the lowest $\mathrm{NaNO}_{3}$ concentration did not negatively affect growth rate, it appears that the lower $\mathrm{NaNO}_{3}$ concentration $(1 / 10$ that in $3 \mathrm{~N}-\mathrm{BB}$ ) may be optimal for large-scale algae oil production. However, this recommendation is tempered by two caveats. First, these experiments were limited to 13 days of culture. Over a longer period of time, even the $S$. dimorphus 
cultures with initially high $\mathrm{NaNO}_{3}$ concentrations will eventually be depleted of nitrogen, and will increase in lipid content (unpublished data). In this circumstance, the overall lipid concentration may then be further increased due to the higher biomass concentration, provided that light limitations do not occur, with the trade-off that a longer period of time is needed. Secondly, there are ways to optimize the process, such as by means of two reactors (or ponds) in series, the first to maximize biomass yield, and the second to accumulate lipids.

These experimental results were conducted in $250 \mathrm{~mL}$ flasks in which every effort was made to ensure that all other operating parameters (light, temperature, shaking, air $/ \mathrm{CO}_{2}$ supply) was consistent among the flasks. In a different, or larger, culture system, one of the above operating parameters may be more limiting for growth, which may suggest that medium concentrations could be reduced even further. Conversely, a greater availability of energy or carbon for growth in an alternative system will require a reexamination of these results and possible upward adjustment of recommended concentrations.

\section{ACKNOWLEDGMENTS}

This work was supported by the Research Experience for Undergraduates program at Cleveland State University.

\section{LITERATURE CITED}

1. Moede, A., Greene, R.W., \& Spencer, D.F. (1980). Effects of selenium on the growth and phosphorus uptake of Scenedesmus dimonphus and Anabaena cylindrica, Environmental and Experimental Botany, 20, 207-212.

2. Yang, Y., \& Gao, K. (2003). Effects of $\mathrm{CO}_{2}$ concentrations on the freshwater microalgae, Chlamydomonas reinhardtii, Cblorella pyrenoidosa and Scenedesmus obliquus (Chlorophyta), Journal of Applied Phycology, 15, 379-389.

3. Shen, Y., Pei, Z., Yuan, W., \& Mao, E. (2009). Effect of nitrogen and extraction method on algae lipid yield, International Journal of Agriculture and Biological Engineering, 2, 51-57

4. Rodolfi, L., Zittelli, G.C., Bassi, N., Padovani, G., Biondi, N., Bonini, G., \& Tredici, M.R. (2009). Microalgae for oil: Strain selection, induction of lipid synthesis and outdoor mass cultivation in a low-cost photobioreactor, Biotechnology and Bioengineering, 102, 100-112.

5. Renaud, S.M., Parry, D.L., \& Thinh, L.V. (1994). Microalgae for use in tropical aquaculture I: Gross chemical and fatty acid composition of twelve species of microalgae from the Northern Territory, Australia, Journal of Applied Phycology, 6, 337-345.

6. Abou-Shanab, R.A.I., Matter, I.A., Kim, S.-N., Oh, Y.-K., Choi, J., \& Jeon, B.-H. (2011). Characterization and identification of lipid-producing microalgae species isolated from a freshwater lake, Biomass and Ioenergy, 35, 3079-3085.

7. Mandal, S., \& Mallick, N. (2009). Microalga Scenedesmus obliquus as a potential source for biodiesel production, Applied Microbiology and Biotechnology, 84, 281-291.

8. Shifrin, N.S., \& Chisholm, S.W. (1981). Phytoplankton lipids: Interspecific differences and effects of nitrate, silicate and light-dark cycles, Journal of Phycology, 17, 374.

9. Widjaja, A., Chien, C.C., \& Ju, Y.H. (2009). Study of increasing lipid production from fresh water microalgae Chlorella vulgaris, Journal of Taiwan Institute of Chemical Engineers, 40, 13-20.

10. Pruvost, J., Van Vooren, G., Le Gouic, B., CouzinetMossion, A., \& Legrand, J. (2011). Systematic investigation of biomass and lipid productivity by microalgae in photo- bioreactors for biodiesel application, Bioresource Technology, 102, 150-158.

11. Ho, S.H., Chen, W.M., \& Change, J.S. (2010). Scenedesmus obliquus $\mathrm{CNW}-\mathrm{N}$ as a potential candidate for $\mathrm{CO}_{2}$ mitigation and biodiesel production, Bioresource Technology, 101, 8725-8730.

12. Tadros, M.G. (1985). Screening and characterizing oleaginous microalgal species from the Southeastern United States: A final subcontract report to the U.S. Department of Energy, SERI/STR-231-2657.

13. Piorreck, M., Baasch, K.H., \& Pohl, P. (1984). Biomass production, total protein, chlorophylls, lipids and fatty acids of freshwater green and blue-green algae under different nitrogen regimes, Phytochemistry, 23, 207-216.

14. Xin, L., Hong-ying, H., Ke, G., \& Jia, Y. (2010). Growth and nutrient removal properties of a freshwater microalga Scenedesmus sp. IX1 under different kinds of nitrogen sources, Ecological Engineering, 36, 379-381.

15. Makareviciene, V., Andruleviciute, V., Skorupskaite, V., \& Kasperoviciene, J. (2011). Cultivation of microalgae Chlorella sp. and Scenedesmus sp. as a potential biofuel feedstock, Environmental Research Engineering and Management, 3, 21-27.

16. Kunikane, S., Kaneko, M., \& Maehara, R. (1984). Growth and nutrient uptake of green algae, Scenedesmus dimorphus, under a wide range of nitrogen/phosphorus ratio. I. Experimental study, Water Research, 18, 1299-1311.

17. Martinez, M.E., Jimenez, J.M., \& El Yousfi, F. (1999). Influence of phosphorous concentration and temperature on growth and phosphorus uptake by the microalga Scenedesmus obliquus, Bioresource Technology, 67, 233-240.

18. Chen, M., Li, J., Dai, X., Sun, Y., \& Chen, F. (2011). Effect of phosphorous and temperature on chlorophyll a contents and cell sizes of Scenedesmus obliquus and Microcystis aeruginosa, Limnology, 12, 187-192.

19. Kathiresan, S., Sarada, R., Bhattacharya, S., \& Ravishankar, G.A. (2007). Culture media optimization for growth and phycoerythrin production from Porphyridium purpureum, Biotechnology Bioengineering, 96, 456-463.

20. US Department of Agriculture, Economic Research Service, http://www.ers.usda.gov/data-products/fertilizeruse-and-price.aspx\#26727. Accessed July 18, 2013.

21. Heintze, S.G. (1968). Manganese-phosphate reactions in aqueous systems and the effects of applications of monocalcium phosphate, on the availability of manganese to oats in an alkaline fen soil, Plant and Soil, 29, 407-423.

22. Marsh, H.V., Evans, H.J., \& Matrone, G. (1963). Investigations of the role of iron in chlorophyll metabolism. I. Effect of iron deficiency on chlorophyll and heme content and on the activities of certain enzymes in leaves, Plant Physiology, 38, 632-638.

23. Allen, M.D., Kropat, J., Tottey, S., Del Campo, J.A., \& Merchant, S.S. (2007). Manganese deficiency in Chlamydomonas results in loss of photosystem II and MnSOD function, sensitivity to peroxides, and secondary phosphorus and iron deficiency, Plant Physiology (Rockville), $143,263-277$

24. Xin, L., Hong-Ying, H., Ke, G., \& Ying-Xue, S. (2010). Effects of different nitrogen and phosphorous concentrations on the growth, nutrient uptake, and lipid accumulation of a freshwater microalgae scenedesmus sp, Bioresource Technology, 101, 5495-5500.

25. Desouky, S.A. (2011). Response of vitamins on the growth criteria and some metabolic activities of stressed Scenedesmus obliquus cultures, Australian Journal of Basic Applied Sciences, 5, 89-99. 